\title{
TRABALHO DE CAMPO EM UNIDADES DE CONSERVAÇÃO COM GEOMORFOLOGIA CÁRSTICA EM MINAS GERAIS
}

\author{
FIELDWORK IN CONSERVATION UNITS WITH KARSTIC \\ GEOMORPHOLOGY IN MINAS GERAIS
}

\section{TRABAJO DE CAMPO EN UNIDADES DE CONSERVACIÓN CON GEOMORFOLOGÍA CÁRSTICA EN MINAS GERAIS}

\begin{abstract}
Daniela Martins Cunha
Doutoranda em Geografia - Tratamento da Informação Espacial pela Pontifícia Universidade Católica de Minas Gerais - PUC-Minas. Professora do Instituto Federal de Educação, Ciência e Tecnologia de Minas Gerais - IFMG/Campus Governador Valadares. daniela.cunha@ifmg.edu.br
\end{abstract}

Recebido para avaliação em 26/01/2018; Aceito para publicação em 20/10/2018.

\section{RESUMO}

Este relato tem por objetivo demonstrar algumas características do relevo desenvolvido nas rochas cársticas através das observações e análises realizadas em trabalho de campo e complementadas por estudos bibliográficos. O trabalho de campo ocorreu nos dias 12 e 13 de setembro de 2017 em unidades de conservação dos municípios de Lagoa Santa, Pedro Leopoldo e Matozinhos no estado de Minas Gerais. Discussões teórico-conceituais foram realizadas sobre a temática durante as disciplinas de Geomorfologia Ambiental e Seminário de Doutorado- Meio Ambiente do Programa de Pós-graduação Stricto Sensu em Geografia - Tratamento da Informação Espacial da Pontifícia Universidade Católica de Minas Gerais. A partir de um roteiro pré-estabelecido e do processo de interação professor-aluno foram realizadas observações, descrições e análises das formas, gênese e dinâmica do relevo local.

Palavras-chave: Ensino-aprendizagem; Paisagens; Cavernas; Pinturas Rupestres.

\section{ABSTRACT}

This report aims to demonstrate some characteristics of the relief developed in karst rocks through the observations and analyzes performed in field work and complemented by bibliographic studies. Fieldwork took place on September 12 and 13, 2017 in conservation units of the municipalities of Lagoa Santa, Pedro Leopoldo and Matozinhos in the state of Minas Gerais. Theoretical-conceptual discussions were carried out on the subject during the disciplines of Environmental Geomorphology and Seminar of Doctorate-Environment of the Postgraduate Program stricto sensu in Geography - Treatment of Spatial Information of the Pontifical Catholic University of Minas Gerais. From a pre-established script and the process of teacher-student interaction, observations, descriptions and analyzes of the forms, genesis and dynamics of the local relief were made.

Keywords: Teaching-learning; Landscapes; Caves; Rock Paintings.

\section{RESUMEN}

Este relato tiene por objetivo demostrar algunas características del relieve desarrollado en las rocas cársticas a través de las observaciones y análisis realizados en trabajo de campo y complementadas por estudios bibliográficos. El trabajo de campo ocurrió los días 12 y 13 de septiembre de 2017 en 
| Daniela Martins Cunha|

unidades de conservación de los municipios de Lagoa Santa, Pedro Leopoldo y Matozinhos en el estado de Minas Gerais. Las discusiones teórico-conceptuales se realizaron sobre la temática durante las disciplinas de Geomorfología Ambiental y Seminario de Doctorado-Medio Ambiente del Programa de Postgrado stricto sensu en Geografía - Tratamiento de la Información Espacial de la Pontificia Universidad Católica de Minas Gerais. A partir de un itinerario preestablecido y del proceso de interacción profesor-alumno se realizaron observaciones, descripciones y análisis de las formas, génesis y dinámica del relieve local.

Palabras clave: Enseñanza-aprendizaje; Paisajes; Cuevas; Pinturas Rupestres.

\section{INTRODUÇÃO}

A apreensão e o domínio dos conhecimentos geográficos perpassam por um processo de evolução, no qual são desenvolvidas capacidades individuais de relacionar e compreender o espaço do entorno. Deste modo, a construção da noção de espaço e a leitura das diferentes paisagens são fundamentais para que uma criança, um adolescente, um jovem ou um adulto desenvolva habilidades para se orientar, se localizar, observar, analisar, descrever e relacionar os mais diferentes aspectos geográficos obtidos a partir de uma paisagem.

Fazendo-se uma ponte entre o processo de ensino-aprendizagem, a mediação pedagógica e o conhecimento geográfico podem-se apresentar o trabalho de campo como uma das mais importantes abordagens metodológicas a ser utilizada pelo docente de geografia em seus mais diferentes níveis de formação. O trabalho de campo na geografia é ao mesmo tempo uma fonte de pesquisa e um recurso metodológico de aprendizagem carregado de particularidades geográficas.

Segundo Serpa (2006), alguns pressupostos básicos garantem a importância teóricometodológica do trabalho de campo para a geografia, sendo eles: 1 - a especificidade que o trabalho de campo tem para a geografia em relação a outras disciplinas, uma vez que o geógrafo consegue analisar tanto as partes como a totalidade do espaço; 2- as possibilidades de operacionalização do trabalho de campo a partir de recortes espaciais, de escalas específicas e de questões e problemas característicos dos fenômenos; 3- o trabalho de campo é instrumento para a superação da dicotomia e ambiguidades típicas da geografia, considera o espaço dinâmico e mutável, onde vários olhares podem surgir sobre as paisagens e, 4- o trabalho de campo permite o estabelecimento da relação entre teoria e método.

Dessa forma, por sua importância e possibilidade de uma aprendizagem na qual o sujeito possa ampliar sua visão em relação ao espaço de seu entorno, foi proposto e 
realizado pela disciplina Seminário de Doutorado - Meio Ambiente, ministrada pelo professor Luiz Eduardo Panisset Travassos do Programa de Pós-graduação em Geografia Tratamento da Informação Espacial da Pontifícia Universidade Católica de Minas Gerais, Dinter UNEC/PUC-Minas, um trabalho de campo em algumas unidades de conservação com geomorfologia cárstica em Minas Gerais. Este relato tem por objetivo demonstrar algumas características do relevo desenvolvido nas rochas cársticas através das observações e análises realizadas em campo e complementadas por estudos bibliográficos.

\section{PROCEDIMENTOS METODLÓGICOS}

O trabalho de campo foi realizado nos dias 12 e 13 de setembro de 2017 em unidades de conservação dos municípios de Lagoa Santa, Pedro Leopoldo e Matozinhos no estado de Minas Gerais, nas quais foi possível realizar estudos da Geografia Física, especificamente da geomorfologia cárstica. O trabalho se baseou em discussões teóricoconceituais que foram realizadas sobre a temática durante as disciplinas de Geomorfologia Ambiental e Seminário de Doutorado - Meio Ambiente do Programa de Pós-graduação em questão. Foi estabelecido pelo docente das disciplinas um roteiro apresentado e explicado aos discentes com antecedência e, através do processo de interação professor-aluno, em campo foram realizadas observações, descrições e análises das formas, gênese e dinâmica do relevo local.

\section{O CAMPO}

A Geomorfologia Cárstica compreende o "estudo da forma, gênese e dinâmica dos relevos elaborados sobre rochas solúveis pela água, tais como as carbonáticas e os evaporitos, e, mesmo rochas menos solúveis, como quartzitos, granitos, basaltos, entre outras” (KOHLER, 2005, p. 309). Na região do campo predominam as rochas carbonáticas.

A primeira parada ocorreu a caminho do Parque Estadual do Sumidouro. Nela foi possível observar formas negativas e positivas do relevo cárstico, como as depressões e os maciços, respectivamente. Ambas são caracterizadas como exocársticas, representam os relevos superficiais, os quais, na maioria das vezes, resultam da evolução do endocarste formas subterrâneas do carste e de domínio da espeleologia (KOHLER, 2005; CASSETI, 2005; TRAVASSOS et al., 2015). 
A segunda parada foi no Parque Estadual do Sumidouro (PESU), criado na década de 1980 pelo Decreto $\mathrm{n}^{\mathrm{o}}$ 20.375, com o objetivo de preservar o patrimônio cultural e natural existente na região. O PESU localiza-se no médio curso do rio das Velhas, na porção central do estado de Minas Gerais, compreendendo terras dos municípios de Lagoa Santa e Pedro Leopoldo, identificados em duas grandes unidades geomorfológicas cársticas, o Poljé do Sumidouro e o Planalto das Dolinas (IEF, 2010; EVANGELISTA; TRAVASSOS, 2015).

Do lado do parque pertencente a Fidalgo, distrito de Pedro Leopoldo, foi possível observar uma vasta área conhecida como Poljé do Sumidouro, com relevo aplainado formado a partir da dissolução de rochas carbonáticas e drenado pelo Córrego Samambaia, um dos pontos de menor altitude com 678 metros (EVANGELISTA; TRAVASSOS, 2015).

Do Poljé observou-se o Maciço do Sumidouro e a planície onde se forma a Lagoa do Sumidouro no período chuvoso, uma vez que na data do trabalho de campo seu nível hídrico estava rebaixado, contudo, mesmo estando seca obteve-se uma dimensão de sua área de inundação. Caminhando em direção ao maciço, próximo à região onde ocorre a formação da lagoa, observou-se um sumidouro. O sumidouro é um "ponto ou local onde a água que escoa na superfície desaparece e passa a ter um escoamento subterrâneo" (TRAVASSOS et al., 2015, p. 59) (Figura 1).

O Maciço do Sumidouro se destaca em meio à planície de inundação, em seu entorno nota-se blocos que resultaram do intemperismo e dissolução da rocha carbonática. Em sua base encontra-se outro sumidouro, em seu paredão a presença de pinturas rupestres e os registros da ação intempérica da água através das diferentes colorações da rocha e da formação de estalactites.

No topo do maciço tem-se o Mirante do Sumidouro a $700 \mathrm{~m}$ de altitude (EVANGELISTA; TRAVASSOS, 2015) com uma visão panorâmica de toda a área: a planície de inundação da Lagoa do Sumidouro, o Córrego Samambaia que é capturado pelo sumidouro da base do maciço, a formação geomorfológica do entorno com colinas de baixa elevação e bem dissecadas, as quais são ocupadas pelo Cerrado ou pelas Matas Secas, sendo as últimas muito presentes no topo e entorno próximo ao maciço (Figura 1).

Em uma das trilhas para o mirante passou-se próximo à entrada de uma caverna, a Gruta do Sumidouro, não aberta à visitação turística. Nela, Peter Lund, em 1843, após uma grande estiagem que ocasionou o esvaziamento da Lagoa do Sumidouro, encontrou uma grande quantidade de ossos de aproximadamente 30 indivíduos humanos de idades diferentes e de um cavalo americano pré-histórico, ambos no mesmo estado de 
decomposição, não deixando nenhuma dúvida sobre a coexistência desses indivíduos no mesmo período, o que contestou a Teoria Criacionista na época.

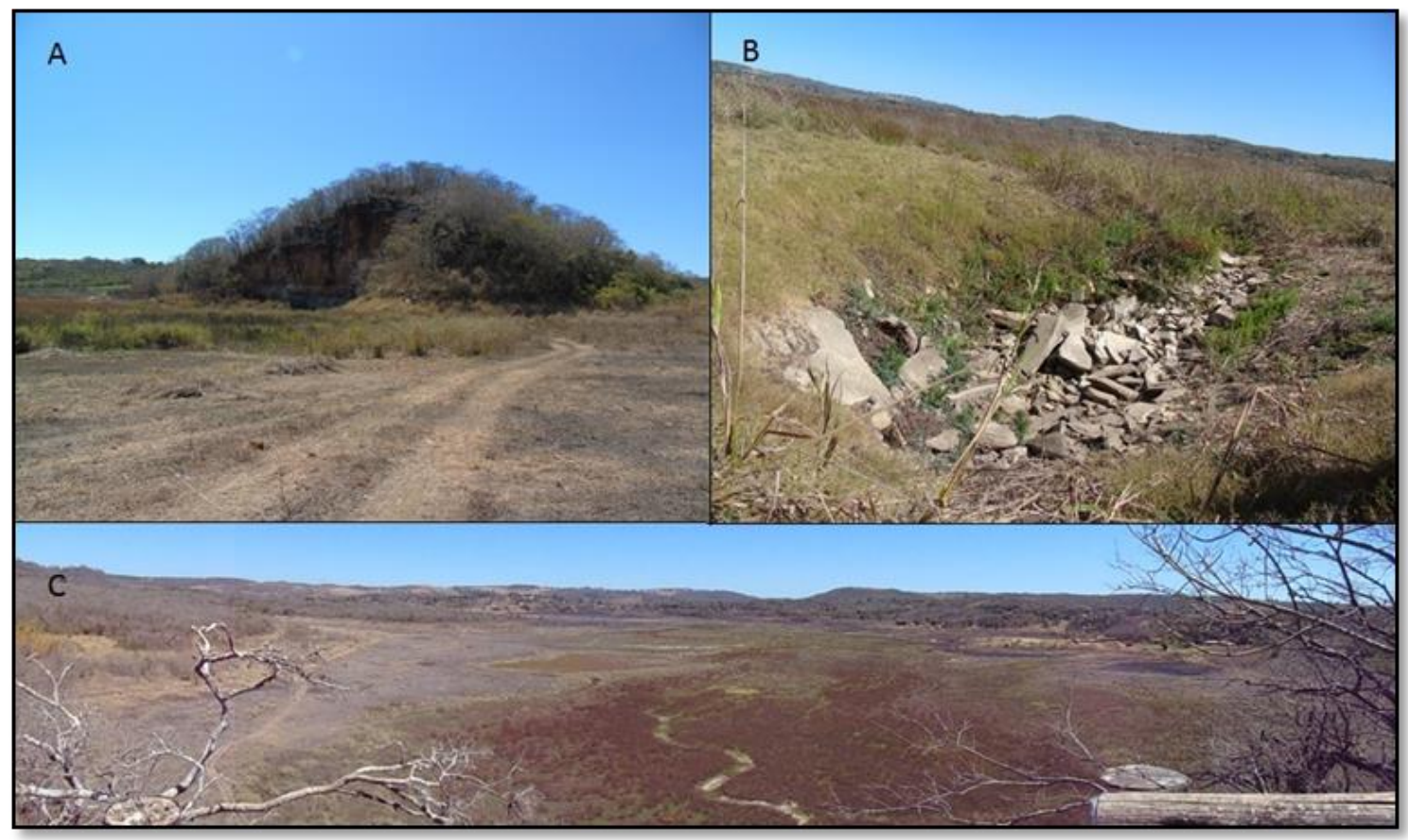

Figura 1 - Maciço do Sumidouro visto do Poljé (A); Sumidouro próximo à área de formação da lagoa (B); Vista da Lagoa do Sumidouro no período seco a partir do Mirante do Sumidouro.

Fonte: Autora, 2017.

A terceira parada ocorreu próxima ao Maciço do Baú, unidade paisagística com $724 \mathrm{~m}$ de altitude localizada na área de amortecimento do PESU e incorporada à unidade geomorfológica do Planalto das Dolinas. O nome do Maciço do Baú “deve-se ao formato alongado que se assemelha a uma "chave" ou "fechadura" de um "baú", aspecto característico da evolução de uma caverna com o canal inicial mais arredondado e seguido pelo rebaixamento do nível de base hídrico" (EVANGELISTA; TRAVASSOS, 2015, p. 75) (Figura 2). 


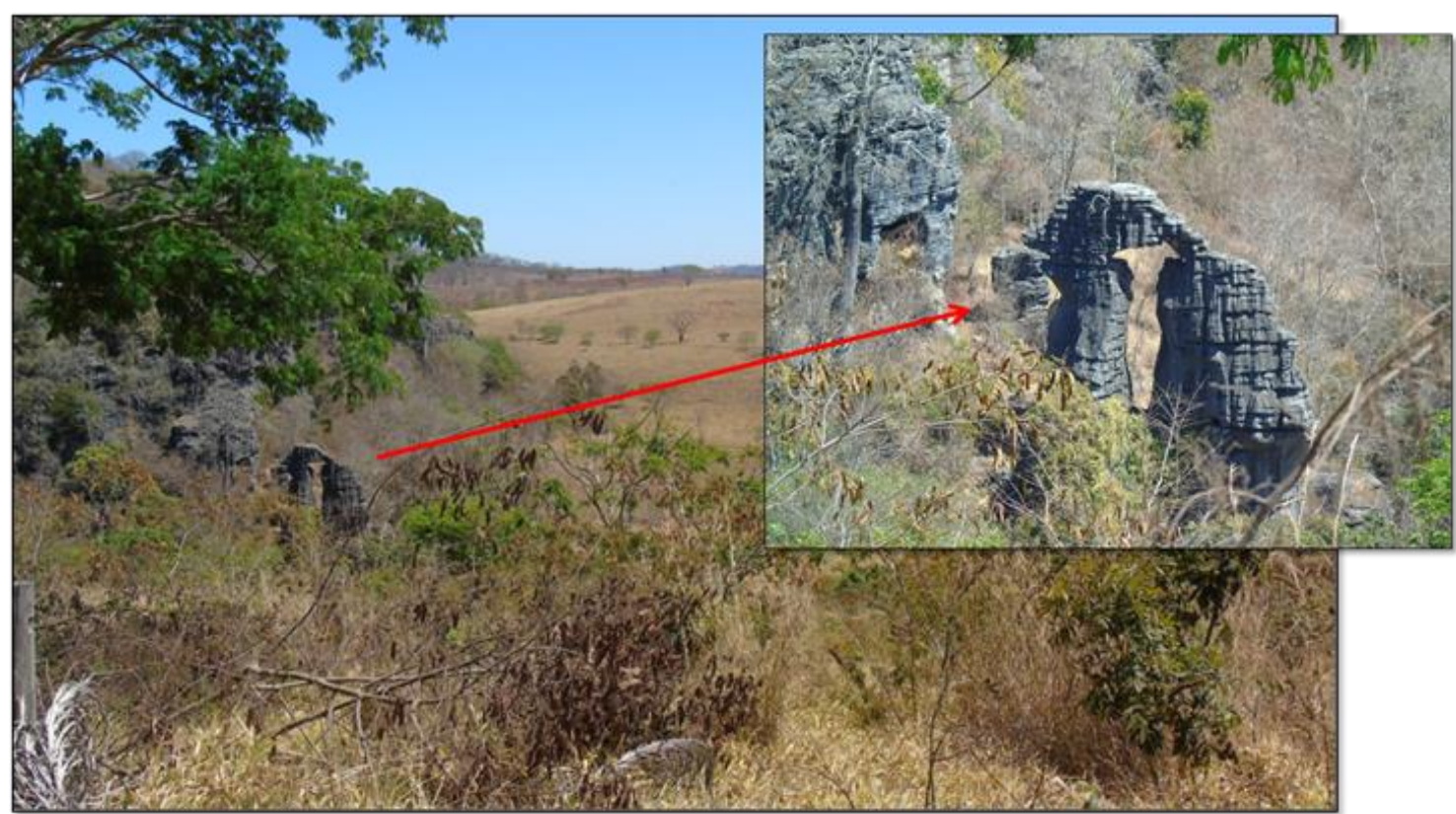

Figura 2 - Vista do Maciço do Baú e em detalhe a geoforma que dá nome ao maciço Fonte: Autora, 2017.

$\mathrm{Na}$ área de mineração desativada da Finacal realizamos a quarta parada. O carste é constituído de rochas carbonáticas (calcário e dolomita), as quais servem de matéria-prima para indústrias de construção civil e indústrias agrícolas, dentre outras. Tal uso econômico/comercial torna essas áreas muito vulneráveis à exploração mineral, conforme se observou no local visitado, onde os cortes nos afloramentos carbonáticos gerados pela atividade da mineração expunham o epicarste. Além disso, pode-se verificar em vários blocos de rochas a presença da calcita, pois se trata de uma área em que este mineral era bem abundante e por isso fora muito explorado (Figura 3).

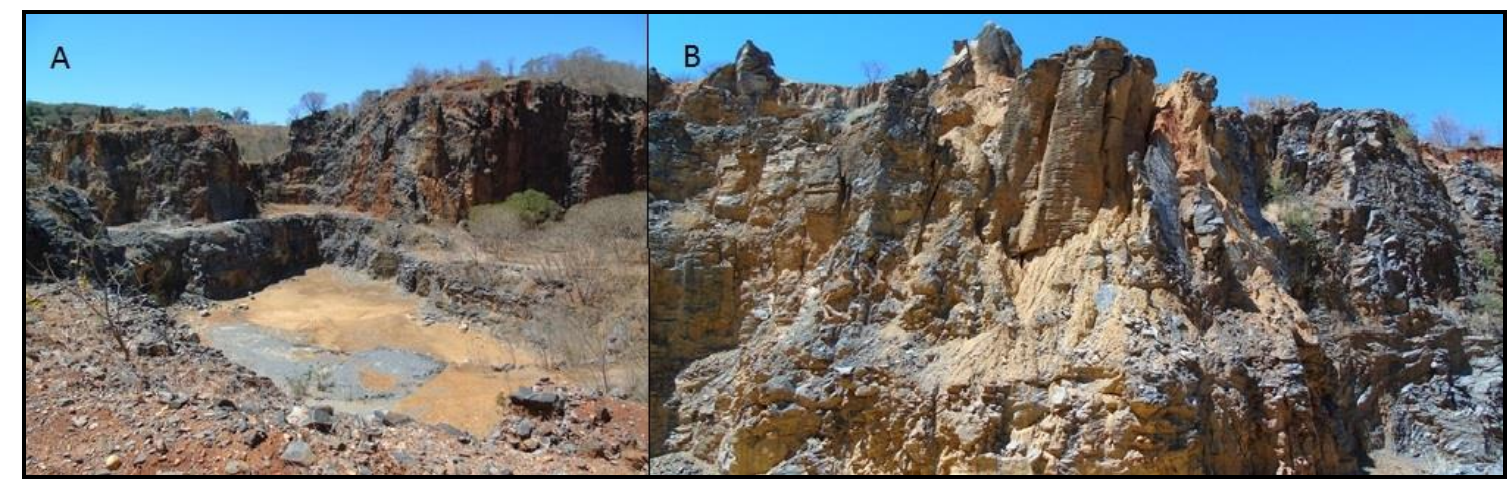

Figura 3 - Vista panorâmica da área de mineração da Finacal (A); Epicarste em um corte realizado pela mineração (B).

Fonte: Autora, 2017.

A quinta parada ocorreu no Monumento Natural Experiência da Jaguara criado pelo decreto $\mathrm{n}^{\mathrm{o}}$ 45.391, de 08 de junho de 2010 e localizado no município de Matozinhos com uma área de 38,4815ha (GOVERNO DO ESTADO DE MINAS GERAIS, 2010). 
| Trabalho de campo em unidades de conservação com Geomorfologia Cárstica em Minas Gerais |

| Daniela Martins Cunha|

No monumento destaca-se o Maciço da Jaguara, marcado por paredões com desníveis praticamente verticais nos quais fica evidente a ação do intemperismo químico nas rochas carbonáticas, de uma beleza cênica encantadora. Em seu interior, evidencia-se também como a dinâmica hidrológica contribuiu e ainda contribui para a origem e formação das cavernas e dos espeleotemas (Figura 4).

As cavernas do maciço visitadas são exuberantes, com desenvolvimento praticamente horizontal e de fácil acesso, onde foi possível observar abatimentos, ou seja, rochas desprendidas das paredes e dos tetos, cavidades nas rochas provocadas pela dissolução do carbonato, estalactites, pequenas colunas, a ação intempérica da vegetação. No entorno do maciço observou-se ambiente parcialmente inundado no qual o aquífero aflora, depressões cársticas conhecidas como dolinas e alguns remanescentes do cerrado, uma vez que no entorno há na atualidade o predomínio da pastagem.

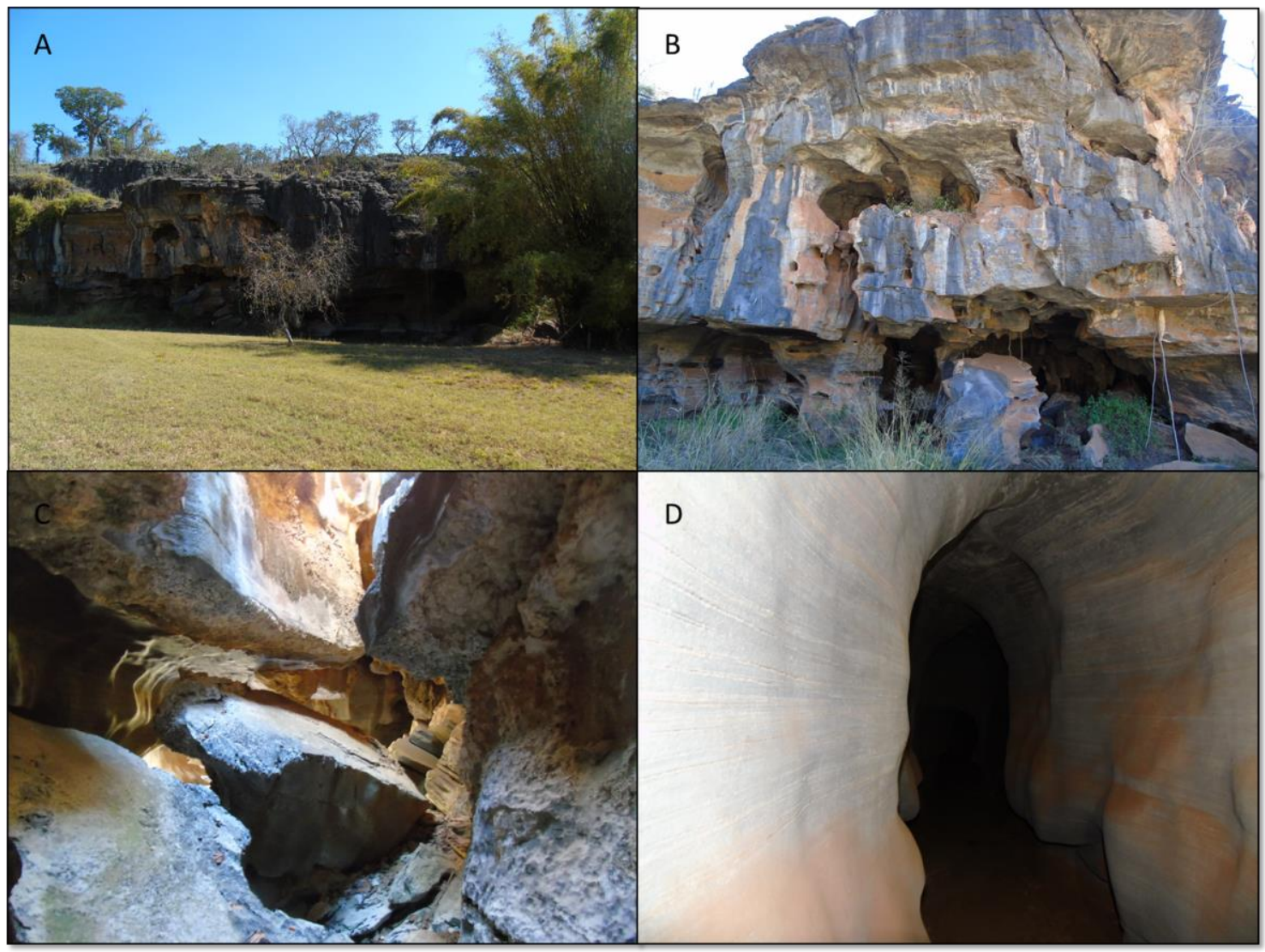

Figura 4 - Feição externa do Maciço da Jaguara (A e B); Cavernas do interior do maciço com seus blocos abatidos (C) e dutos da dissolução do carbonato (D).

Fonte: Autora, 2017.

A sexta e última parada ocorreu no dia 13 de setembro no Parque Estadual da Cerca Grande localizado no distrito de Mocambeiro, município de Matozinhos. Foi criado 
pelo Decreto Estadual no 45.398 de 14 de junho de 2010, com uma área de 134,1915ha e um perímetro de $6.908,94 \mathrm{~m}$ (IEF, 2017).

"Na região de Lagoa Santa, Cerca Grande foi uma das primeiras grutas a ser pesquisada por Lund e, também, tema de seu segundo tratado, em 1837. Na rocha Lund viu pela primeira vez as pinturas dos "selvagens" que Brandt copiou para seu tratado" (HOLTEN; STERLL, 2011 apud PÔSSAS et al., 2012, p. 30). As magníficas pinturas rupestres referidas foram vistas no campo. Elas fazem com que o parque seja o único sítio arqueológico de Minas Gerais tombado pelo IPHAN em nível nacional. Esta região é considerada o berço da espeleologia, arqueologia e paleontologia brasileira (IEF, 2017).

Além da imensa e encantadora beleza dos painéis de pinturas rupestres, o maciço calcário de Cerca Grande fascina pela dimensão e altura. Em seus paredões é possível visualizar a estratificação das rochas calcárias em planos ora horizontais, ora subhorizontais, a presença de sumidouro, de escalopes que indicam a direção dos fluxos de água. Na parte externa do maciço também se observa a presença de torres calcárias, fendas nas rochas que formam cavidades naturais, várias entradas para grutas e a presença da mata seca e de vastas áreas de pastagem (Figura 5).

Caminhando no interior do maciço e tendo por referência o tamanho das pessoas se tem maior proporção da sua dimensão e das árvores ali encontradas que atingem a mesma altura. Observam-se dutos de água esculpidos na rocha, a presença de grandes blocos abatidos, amplos salões com espeleotemas como estalactites, estalagmites, cortinas e escorrimentos (Figura 5). 


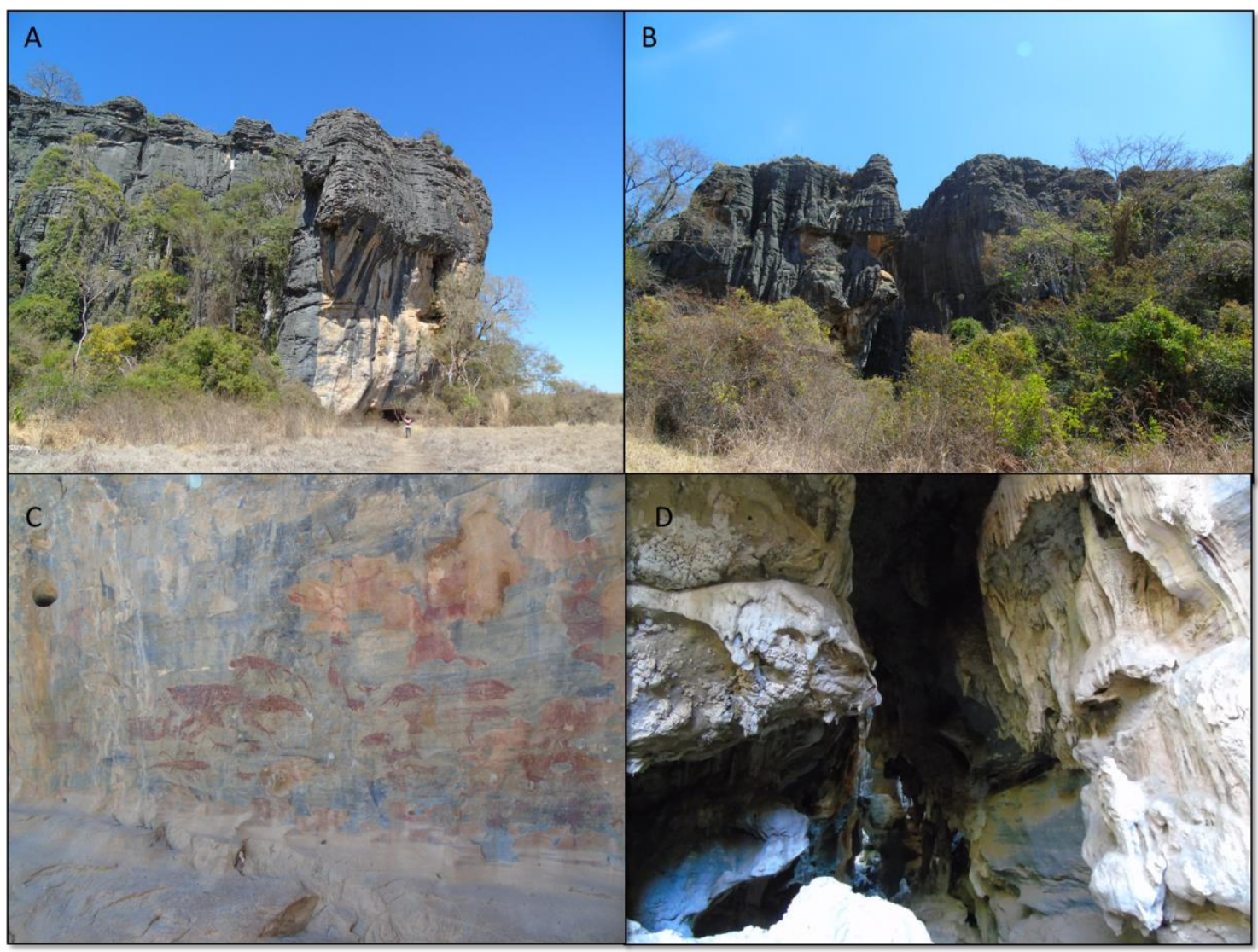

Figura 5 - Vista externa do Maciço da Cerca Grande (A e B); Parte do painel de pinturas rupestres (C); Caverna do maciço com espeleotemas (D).

Fonte: Autora, 2017.

\section{CONSIDERAÇÕES FINAIS}

O trabalho de campo permitiu assimilar na prática importantes conceitos da disciplina. E, além disso, demonstrar a importância da integração dos conhecimentos geográficos, os quais devem ser compreendidos por uma ótica de integração, de interdisciplinaridade, sendo o trabalho de campo, o principal recurso metodológico a serviço da Geografia para se alcançar tais objetivos.

Por fim, depois de visualizar e se encantar com toda a beleza das formas esculpidas nas rochas cársticas, se reafirma a importância de preservar estas áreas, muitas vezes expostas a poluição tanto por resíduos sólidos como líquidos provenientes das áreas urbanas e rurais. E, também sujeitas a abatimentos e destruição de seus sítios ocasionados pela presença de mineradoras em seu entorno, as quais exploram o calcário e a dolomita presentes nessas rochas.

\section{REFERÊNCIAS}

$\begin{array}{llllll}\text { InterEspaço Grajaú/MA } & \text { v. 4, n. } 14 & \text { p. 280-289 } & \text { maio/ago. } 2018 & \text { Página } 288\end{array}$


CASSETI, Valter. Geomorfologia. 2005. Disponível em: < http://www.funape.org.br/geomorfologia/>. Acesso em: 21 set. 2017.

EVANGELISTA, V. K.; TRAVASSOS, L. E. P. Estratégias para o geoturismo e geoconservação no Parque Estadual do Sumidouro, Minas Gerais. Brazilian Geographical Journal: Geosciences and Humanities research medium, Ituiutaba, v. 6, n. 2, p. 67-79, jul./dez. 2015.

GOVERNO DO ESTADO DE MINAS GERAIS. Decreto $\mathbf{n}^{\mathbf{0}} \mathbf{4 5 . 3 9 1}$, de $\mathbf{0 8}$ de junho de 2010. Cria o Monumento Natural Estadual Experiência da Jaguara e declara de utilidade pública para desapropriação de pleno domínio terrenos e benfeitorias no Município de Matozinhos. Disponível em: < http://www.siam.mg.gov.br/sla/download.pdf?IdNorma= $\underline{13510}>$. Acesso em: 23 set. 2017.

IEF/MG - INSTITUto ESTADUAL DE FLORESTAS. Plano de Manejo do Parque Estadual do Sumidouro. Lagoa Santa - Pedro Leopoldo: IEF/GHEOSFERA, 2010.

Parque Estadual Cerca Grande. Disponível em: <http://www.ief.mg.gov.br/areas-protegidas/parques-estaduais/1414>. Acesso em: 25 set. 2017.

KOHLER, H. C. Geomorfologia Cárstica. In: GUERRA, A. J. T.; CUNHA, S. B. da. Geomorfologia: Uma atualização de bases e conceitos. 6. ed. Rio de Janeiro: Bertrand Brasil, 2005.

PÔSSAS, I. B.; TRAVASSOS, L. E. P.; RODRIGUES, B. D. Registros de Peter W. Lund sobre a região do carste de Lagoa Santa, Minas Gerais: possibilidades para o turismo pedagógico e científico. Tourism and Karst Areas, Campinas, SéTur/SBE., v. 5, n. 1, p. 25-33, 2012.

SERPA, Â. O trabalho de campo em geografia: uma abordagem teórico-metodológica. Boletim Paulista de Geografia, São Paulo, n. 84, p. 7-24, 2006.

TRAVASSOS, L. E. P.; RODRIGUES, B.D.; TIMO, M.B. Glossário conciso e ilustrado de termos cársticos e espeleológicos. Belo Horizonte: PUC Minas, 2015. 65 p. 